\title{
X-ray satellite faces its final showdown
}

Rome. The completion of Italy's X-ray satellite, SAX, is hanging in the balance amid continuing controversy over the improper use of funding, major cost increases and lengthy delays. Many scientists are complaining that, even if a new launch date of 1995 is met, the satellite will already be outdated when it is launched.

Initially planned in the early 1980 s as the country's first scientific satellite, SAX has long provoked bitter arguments in Italy's scientific community. It will carry detectors for both soft and hard X-rays, and is intended to complement data obtained from other X-ray satellites.

But many of Italy's space physicists have complained at the way the project - which has already cost 300 billion lire (\$US184 million) and whose final cost could be between L600 and L 720 billion - has been absorbing an ever-increasing proportion of the country's space science budget.

Last year, for example, scientists from the science committee of the Italian Space Agency (ASI) complained that about twothirds of the money allocated for basic research in the agency's budget in $1991 \mathrm{had}$ gone towards developing instruments for SAX, and had not gone through established evaluation processes.

There are also suspicions that not all of the extra funds have gone towards paying for increased development costs. No impropriety has been proved. But Italy's courts are already investigating allegations of financial irregularities and possible corruption within the space agency ASI and the main contractor for SAX, Alenia Spazio.

Last week, ASI's former president, Luciano Guerriero, and director-general Carlo Buongiorno, along with the whole of the ASI board, were indicted under suspicion of misusing L3 billion to fund, among other things, parties held by different political parties. Other indictments may follow.

Italy's new research minister, Umberto Colombo, is reassessing the whole SAX project. If he cannot be convinced that plans to complete the satellite within two years can be achieved within an acceptable budget, he could order it to be abandoned.

Formal planning for SAX began in 1982. At that time, the launch date was put at 1988 or 1989 , and the total cost estimated at L100 million, shared equally by the Italian and Dutch governments. (One of its detectors is being developed for the European Space Agency at its operations centre (ESTEC) in the Netherlands, and the satellite will also carry two Dutch wide-field cameras.)

By 1988, when ASI took over the project from Italy's National Research Council, the cost had risen to L478 billion, with a launch date of 1992. The Dutch contribution had been limited to around US\$35 million.

In July 1990, ASI signed a contract with
Alenia Spazio agreeing to pay L418.5 million for the construction of SAX, a price that excludes the cost of launch and ground operations. Remo Ruffini, former chairman of ASI's science committee, says the total cost is likely to be L723 billion.

At least part of the price rise can be attributed to a redesign following the shuttle disaster in 1986, when it was decided to move from NASA's shuttle to an expendable launcher. Colombo also argues that the costs inevitably grew as the satellite was designed in more detail.

Colombo must now decide whether to

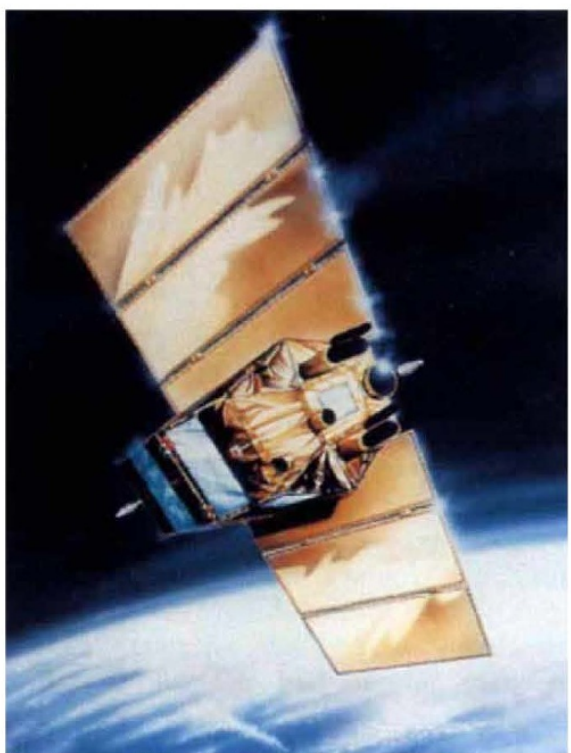

SAX should look like this.

pay at least another L300 billion to let SAX fly. Many scientists have doubts about whether it should proceed, even at this late stage. Salvatore Serio, director of the Palermo Observatory in Italy, says that the range of $\mathrm{X}$-rays that can be measured by SAX has already been covered by several other recently launched X-ray satellites, including the German ROSAT mission, the Japanese satellites Ginga and Asca, and the US-led Gamma-Ray Observatory.

"I feel very uneasy about SAX," Serio says, "Italy needs to evaluate very carefully whether the science to be addressed is still worth the money we have yet to spend on it." Joachim Trümper, head of the ROSAT programme, claims that the project is being driven by industry and is no longer in the forefront of X-ray astronomy.

Stuart Bowyer, director of the Centre for Extreme UV Astrophysics at the University of California, Berkeley, also questions the value of the project. "It is hard to imagine Europe, the US or Japan running this sort of mission at the moment", he says.

Those directly involved, however, continue to defend its scientific worth. Arvind Parmar, project manager of ESTEC's low energy X-ray detector, says that SAX will be unique in its ability to provide a wide range of measurements simultaneously. And Johan Bleeker, director of the Netherlands Organization for Space Research, says it would be a "disaster" if the mission was stopped. The Dutch instruments could not be used on another project, and Holland's investment would therefore be wasted.

According to Giuseppe Viriglio, deputy manager in charge of operations at Alenia Spazio, development work on SAX is now complete. Mechanical stress and electrical compatibility tests on two different models should be finished by the end of the year, and the whole system ready for putting together by next April.

Alessandro Bellini, managing director of Alenia's subsidiary Laben, which is responsible for the scientific instruments being built by Italy, says that companies carrying out the development contracts should not be blamed for the delays in the programme, pointing out that these occurred before the contracts were signed.

If final verification tests are successful, Viriglio says the satellite will be ready for launch by April 1995. But, speaking privately, many scientists feel that this date is optimistic, particularly since the decision not to build an experimental model of the satellite, apparently to save money, has, they claim, increased the risk of failure in the current engineering model.

Last February, former research minister Sandro Fontana ordered an investigation into ASI's handling of its research funds, including those allocated to the SAX programme. A group of five 'wise men' including Colombo - concluded that delaying the launch date beyond 1994 would reduce the scientific impact of the mission unacceptably

In September, Colombo - who as research minister is now having to look at the value of a programme with a launch date of 1995 - replaced the ASI board at the end of its five-year term of office with a commission headed by physicist Gian Pietro Puppi, aided by officials from the Court of Accounts and the State Council.

One of the tasks of the new commission is to analyse what has gone wrong with SAX. A team of scientists was called in two weeks ago to help with the analysis, and a report will be completed by the end of the year.

The conclusions will play an important role in Colombo's decision on whether SAX should still go ahead - - or whether, at a total cost of US\$400 million (considerably higher than the more ambitious ROSAT, which cost $\$ 325$ million), continuation would be an excessive price for Italy to pay in its current economic situation.

Alison Abbott 